\title{
Effectiveness and Tolerability of Vildagliptin and the Single Pill Combination of Vildagliptin and Metformin in "Real-World" Management of Type 2 Diabetes Mellitus: The G-FORCE Study
}

\author{
Luc Van Gaal · Michel P. Hermans · Evis Daci · Kris Denhaerynck · \\ Lut De Meester · Karen MacDonald · Ivo Abraham · Stefaan Vancayzeele • \\ Michael Maris
}

Received: February 20, 2019 / Published online: March 27, 2019

(C) The Author(s) 2019

\section{ABSTRACT}

Introduction: Randomized clinical trials showed that vildagliptin is well tolerated and leads to clinically meaningful decreases in glycated hemoglobin (HbA1c) and fasting plasma glucose (FPG) both in monotherapy and as addon therapy in inadequately controlled type 2 diabetes mellitus (T2DM) patients. Nevertheless, there is an increased interest for real-life studies to confirm the clinical trial findings in the setting of a daily clinical practice. The aim of this

Enhanced Digital Features To view enhanced digital features for this article go to https://doi.org/10.6084/ m9.figshare.7831796.

L. Van Gaal

Department of Endocrino-Diabetology, Antwerp University Hospital, Wilrijkstraat 10, 2650 Edegem, Belgium

\section{P. Hermans}

Cliniques Universitaires Saint-Luc, Avenue

Hippocrate 10, 1200 Woluwe-Saint-Lambert, Belgium

E. Daci · L. De Meester - S. Vancayzeele .

M. Maris $(\square)$

Novartis Pharma nv-sa, Medialaan 40, 1800

Vilvoorde, Belgium

e-mail: michael.maris@novartis.com

K. Denhaerynck · K. MacDonald · I. Abraham Matrix45, 6159 W Sunset Rd, Tucson, AZ 85743, USA study was to evaluate the effectiveness and tolerability of vildagliptin in a real-life clinical setting and to explore factors determining drug adherence and T2DM management.

Methods: G-FORCE was a prospective, observational, open-label, multi-center study in which T2DM patients were prescribed de novo vildagliptin. Clinical effectiveness was determined by changes in HbA1c and FPG and by the proportion of patients reaching glycemic goal. Data were collected at baseline, after $105 \pm$ 15 days and after $180 \pm 15$ days.

Results: A total of 1230 patients were included in this analysis. Mean age was $63.9 \pm 10.8$ years, and mean HbA1c and FPG levels were $8.2 \pm$ $1.3 \%$ and $171.0 \pm 53.3 \mathrm{mg} / \mathrm{dL}$, respectively. At

\author{
I. Abraham \\ Center for Health Outcomes and Pharmaco- \\ Economic Research, University of Arizona, $1295 \mathrm{~N}$ \\ Martin, Tucson, AZ 85721, USA \\ I. Abraham \\ Department of Pharmacy Practice and Science, \\ University of Arizona, 1295 N Martin, Tucson, \\ AZ 85721, USA \\ I. Abraham \\ Department of Family and Community Medicine, \\ University of Arizona, 655 N Alvernon, Suite 228, \\ Tucson, AZ 85711, USA
}


180 days of treatment, HbA1c and FPG levels decreased to $7.2 \pm 1.0 \%$ and $141.1 \pm 44.0 \mathrm{mg} /$ $\mathrm{dL}$, respectively, while the proportion of patients reaching HbA1c and FPG goals rose from 8.6 to $44.6 \%$ and from 14.2 to $42.8 \%$, respectively.

Conclusion: In this real-world study, vildagliptin was an effective and safe treatment for T2DM patients already treated with metformin, while the single pill combination of vildagliptin and metformin provides a convenient alternative while ensuring comparable effectiveness and tolerability.

Funding: Novartis Pharma.

Keywords: DPP4i; HbA1c; Real-world; T2DM; Type 2 diabetes; Vildagliptin

$\begin{array}{ll}\text { Abbreviations } \\ \text { ALT } & \text { Alanine aminotransferase } \\ \text { AST } & \text { Aspartate aminotransferase } \\ \text { FPG } & \text { Fasting plasma glucose } \\ \text { GLP-1 } & \text { Glucagon-like peptide-1 } \\ \text { Hba1c } & \text { Glycated hemoglobin } \\ \text { HDL } & \text { High-density lipoprotein } \\ \text { LDL } & \text { Low-density lipoprotein }\end{array}$

\section{INTRODUCTION}

Type 2 diabetes mellitus (T2DM) is a chronic and progressive disease. Only $50 \%$ of individuals with T2DM achieve glycemic control defined by a glycated hemoglobin (HbA1c) target of $<7 \%$. This hyperglycemia, if left insufficiently treated, can cause damage to various body organs, leading to life-threatening complications, such as cardiovascular disease, neuropathy, nephropathy and retinopathy [1]. Whereas type 1 diabetes mellitus (T1DM) is characterized by an auto-immune response that in turn is characterized by insulin deficiency due to pancreatic beta cell loss [2], T2DM is caused by progressively impaired insulin secretion by pancreatic beta cells, usually upon a background of pre-existing insulin resistance in skeletal muscle, liver and adipose tissue [3]. T2DM is far more common (accounting for $>90 \%$ of all DM cases) than either T1DM or gestational diabetes. In 2017, an estimated 425 million people worldwide were living with $\mathrm{T} 2 \mathrm{DM}$, and this figure is projected to rise to 629 million by 2045 [1].

According to a consensus report by the American Diabetes Association (ADA) and the European Association for the Study of Diabetes (EASD), the goals of treatment for T2DM are to prevent or delay complications and to maintain quality of life. This therapeutic strategy requires control of glycemia and cardiovascular risk factor management, regular follow-up and, importantly, a patient-centered approach to enhance patient engagement in self-care activities. Although preserving and enhancing beta cell function is perceived as the holy grail of diabetes treatment, effective techniques are still inadequately developed [4]. Several landmark trials clearly showed that lower HbA1c levels are associated with reduced onset or progression of a number of microvascular complications $[5,6]$. A reasonable glycemic goal recommended by both the ADA and EASD for many adults is a HbA1c level of $<7 \%$, but numerous aspects must be considered when setting glycemic targets, and each target must be individualized to the needs of each patient and his or her disease factors. Lifestyle interventions, including medical nutrition therapy and physical activity, are effective and safe treatment options for improving glucose control in individuals with T2DM. For these reasons, they are recommended as first-line therapies from the time of diagnosis and as cotherapy for patients who also require glucose-lowering medications. Lifestyle management should be part of the ongoing discussion with individuals with T2DM at each visit [4]. Ultimately, most patients will require pharmacotherapy with multiple agents to achieve successful glycemic control [7].

Currently, there are nine major classes of glucose-lowering drugs approved for clinical use in Belgium of which six drugs, i.e. metformin, sulphonylurea, glinides, glitazones, dipeptidyl peptidase-4 inhibitors (DPP-4i) and sodium glucose co-transporter two inhibitors (SGLT2i) are oral glucose-lowering agents with different mechanisms of action. Metformin, if not contraindicated and if tolerated, is the preferred initial pharmacologic agent for the treatment of 
T2DM, while a patient-centered approach should be used to guide the choice of additional pharmacologic agents [8].

Vildagliptin is a potent selective inhibitor of the enzyme dipeptidyl peptidase-4 (DPP-4), which is responsible for the rapid degradation of circulating glucagon-like peptide- 1 and glucose-dependent insulinotropic peptide [9]. Mechanistic studies have shown that vildagliptin improves islet function in patients with T2DM by increasing both alpha and beta cell responsiveness to glucose $[10,11]$. The clinical efficacy of vildagliptin in reducing $\mathrm{HbA1c}$ is well established [12-17], and the safety and tolerability profile has been shown to be excellent compared to sulfonylurea or thiazolidinedione therapy $[14,16]$.

Most of the studies demonstrating the efficacy and effectiveness of vildagliptin in patients with T2DM are randomized controlled trials. While metformin is still the most prescribed glucose-lowering agent, the use of DDP-4i as a second-line treatment has strongly increased over the years, while the use of sulphonylureas and glitazones has decreased [18-21]. Nevertheless, data on the effectiveness of managing hyperglycemia in T2DM with vildagliptin with or without metformin is limited in clinical practice. Further, managing T2DM with subsequent switch to the single pill combination (SPC) vildagliptin/metformin is not fully understood in terms of clinical outcomes and associated patient- and clinician-level determinants. The G-FORCE study was conducted to gain a better understanding of the real value of treatment with the DPP-4i vildagliptin. The objective of this study was to evaluate the effectiveness and tolerability of vildagliptin in a real-life clinical setting and to explore patientand physician determinants of glycemic outcomes.

\section{METHODS}

\section{Study Design}

G-FORCE was a prospective, observational, open-label, single-arm, multi-center study of practice patterns, lifestyle behaviors and clinical outcomes in patients with T2DM for whom the treating physician, per best clinical judgment, decided to prescribe de novo vildagliptin at baseline (visit 1). Per the inclusion criteria, all patients had been treated with metformin, with or without other agents, prior to enrollment. The study included three time points: baseline (visit 1), $105 \pm 15$ days (visit 2) and $180 \pm 15$ days (visit 3). In accordance with local regulations, patients could be switched to the SPC vildagliptin/metformin after 3 months.

The study was approved by the Medical Ethical Committee of Antwerp University Hospital (Belgium). All procedures performed in studies involving human participants were in accordance with the ethical standards of the Antwerp University Hospital (Belgium) and with the 1964 Helsinki declaration and its later amendments or comparable ethical standards. All subjects (or their legal guardian) gave written informed consent before participating in the study. Participation in this study did not affect individual treatment according to medical needs of the patients. The procedures and decisions of the physicians were not influenced and there were no required tests or other assessments to be done other than those performed in routine clinical practice.

\section{Study Population}

A total of 1480 patients were enrolled in 314 primary care practices. Eligible participants were patients diagnosed with T2DM who had been treated with metformin, with or without other agents, prior to enrollment. The T2DM of all patients was considered to be inadequately controlled by this therapy by the treating physician. Consequently, the physician decided upon a therapy with vildagliptin as add-on to metformin or a switch to the SPC of metformin and vildagliptin after 3 months of treatment with both mono-components, according to the local reimbursement criteria. As this was an observational study, all data recorded were available from routine clinical practice. Excluded from the study were patients with prior vildagliptin or vildagliptin/metformin treatment, patients requiring insulin therapy and 
patients exposed to any investigational agent in the 30 days prior to enrollment. The evaluable sample included only those patients for whom at least one HbA1c level was recorded at either visit 2 or visit 3 .

The study duration was 180 days, and the patients were evaluated three times: baseline (visit 1) and after approximately $105 \pm 15$ days (visit 2) and $180 \pm 15$ days (visit 3). The following patient data were collected at entry into the study: socio-demographic data, relevant physical examination data, medical history data, history of present disease, comorbidities, risk factors, lifestyle behaviors, diabetes medications and concomitant medications. Baseline physician data, including socio-demographic data, medical education and specialization, practice environment (including patient mix and volume), knowledge of best practice guidelines and use of evidence-based practice guidelines, were also collected. For the data in the guidelines, questionnaires used in hypertension studies were adapted to the diabetes context [22].

The primary effectiveness outcomes were HbA1c level, goal achievement of HbA1c $<7 \%$, fasting plasma glucose (FPG) level and goal achievement of FPG $<126 \mathrm{mg} / \mathrm{dL}$. Secondary outcomes of interest were body mass index (BMI); waist circumference; levels of total cholesterol, low- (LDL) and high-density (HDL) lipoprotein cholesterol and triglycerides; blood pressure; and alanine (ALT) and aspartate aminotransferase (AST) levels. Blood pressure was measured with the individual in a sitting position, with the arm supported at heart level, and using an appropriately sized cuff for a total of three times, starting at least $5 \mathrm{~min}$ after the start of each visit and repeated at 2- to 3-min intervals. The mean of the three measurements was recorded without rounding off. All of these parameters were measured at all three visits. All laboratory data were collected as available in routine clinical practice, and no central laboratory was used.

Changes in glucose-lowering therapy and the occurrence of adverse events (AE) and serious adverse events (SAE) were also documented. At visits 2 and 3, patients were asked to provide details of any such events experienced since the prior visit.

\section{Medication Adherence}

A modification of the Basel Assessment of Adherence Scale [23] was used to query patients about their medication adherence in the 4 weeks preceding each study time point. These queries focused on: (1) having not taken medication; (2) having skipped several doses or taken dose(s) $\geq 2$ hours off schedule. Each of these queries were scored in terms of frequency $(0=$ adherent to $5=$ non-adherent $)$ and then averaged to yield a composite adherence score of 0-5. Additionally, a single-item visual analog scale (VAS; $10 \mathrm{~cm}$, converted to $0-100 \%$ ) was used to collect physicians' perception of each patient's adherence to their glucose-lowering medication (on a $0-100 \%$ scale); and a VAS was also used to record patients' self-reported adherence to their glucose-lowering medication.

\section{Statistical Analysis}

All data were analyzed using SAS version 9.1 software (SAS Institute, Cary, NC, USA). Statistical significance was set at $p<0.05$. Descriptive statistics of frequency, central tendency and dispersion were used to describe the variables of interest being considered at the applicable levels of measurement. As described previously [22], each participating physician recruited several patients, and therefore patients could not be considered independent but instead 'nested' under their treating physician. A linear mixed model for normally distributed data and logistic regression with generalized estimation equations for other data, such as dichotomous/ ordinal control rates, were applied.

\section{RESULTS}

\section{Patients}

The flow of patients in the study is shown in Fig. 1. Of the 1587 patients initially screened, 


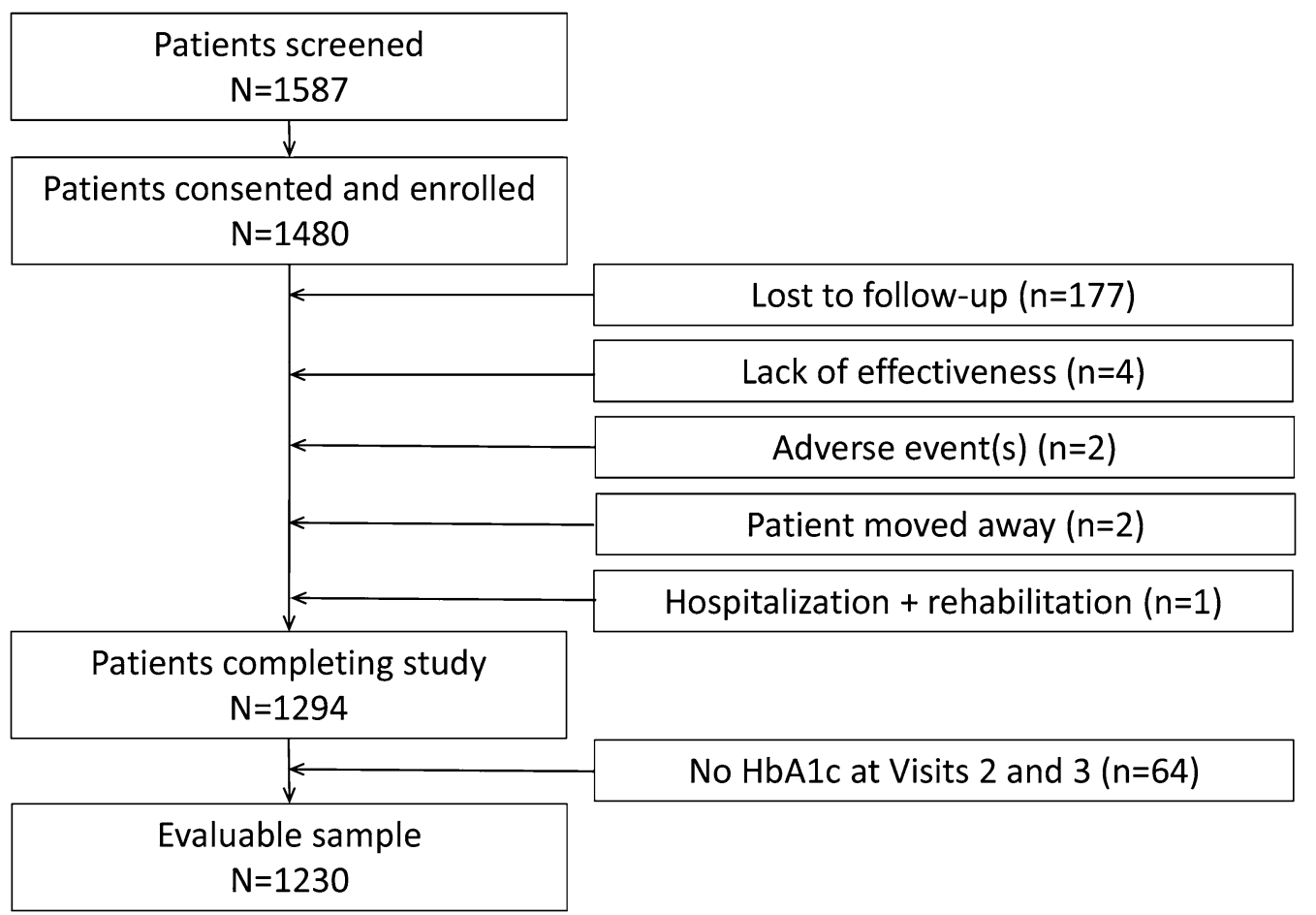

Fig. 1 Flowchart of patient recruitment and disposition. HbAlc Glycated hemoglobin

1480 gave written informed consent, of which 1294 completed the study. For 64 patients, no HbA1c measurement was available for at least one of the two follow-up visits. Thus, the evaluable sample consisted of 1230 patients contributed by 314 physician-investigators.

The clinical baseline characteristics of the patients prior to the initiation of vildagliptin are given in Table 1 . The mean age of the patients was $63.9 \pm 10.8$ years; $45.1 \%$ of the patients were aged $\geq 65$ years and $58.1 \%$ were male. Mean BMI was $30.2 \pm 5.6 \mathrm{~kg} / \mathrm{m}^{2}$, mean body weight was $87.0 \pm 17.0 \mathrm{~kg}$ and mean waist circumference was $106.9 \pm 16.8 \mathrm{~cm}$. The mean time since diagnosis of T2DM was $6.6 \pm 5.8$ years, and at the time of enrollment mean HbA1c and FPG were $8.2 \pm 1.3 \%$ and $171.0 \pm 53.3 \mathrm{mg} / \mathrm{dL}$, respectively. LDL, HDL and triglycerides levels were $107.0 \pm 38.2$, $50.4 \pm 18.8$ and $180.6 \pm 93.8 \mathrm{mg} / \mathrm{dL}$, respectively. ALT and AST levels were $29.3 \pm 20.3$ and $34.4 \pm 27.6 \mathrm{U} / \mathrm{L}$ respectively, whereas mean systolic and diastolic blood pressure were $135.2 \pm 12.8$ and $80.7 \pm 8.4 \mathrm{mmHg}$, respectively. Many patients were diagnosed with comorbidities, of which the most prevalent were dyslipidemia (71.9\%); cardiac pathology (23.2\%), defined as myocardial infraction, heart failure, revascularization, etc.; renal pathology (14.1\%), defined as micro-albuminuria or elevated creatinine; peripheral artery disease $(12.3 \%)$; and psychiatric disorder (12.3\%). The majority of patients had cardio-metabolic risk factors, such as lack of exercise (72.4\%), abdominal obesity, based on physician's judgement $(71.4 \%)$, persistent high carbohydrate intake despite the diabetes diagnosis (56.6\%), a family history of diabetes (39.1\%) and to a lesser extent, smoking (18.3\%) and excessive alcohol intake $(16.3 \%)$.

\section{Physician-Investigators}

The majority of the 314 physician-investigators were male $(81.0 \%)$ and practicing solo $(79.3 \%)$ to a mixed population of patients of all ages $(82.0 \%)$. They were on average $50.9 \pm 9.4$ years old and had been practicing medicine for $25.5 \pm 10.0$ years. The median number of T2DM patients seen in the past year was 70 , of 
Table 1 Patient demographics and clinical status

\begin{tabular}{ll}
\hline Patient demographics and clinical status & Values \\
\hline Demographics & \\
Gender $(\%)$ & 58.1 \\
$\quad$ Male & 41.9 \\
Female & $63.9 \pm 10.8$ \\
Age (mean $\pm \mathrm{SD})($ years $)$ & $54.9 \%$ \\
$<65$ & $45.1 \%$ \\
$\geq 65$ & $87.0 \pm 17.0$ \\
Body weight $(\mathrm{kg})$ & $30.2 \pm 5.6$ \\
Body mass index $\left(\mathrm{km} / \mathrm{m}^{2}\right)($ mean $\pm \mathrm{SD})$ & $106.9 \pm 16.7$ \\
Waist circumference $(\mathrm{cm})($ mean $\pm \mathrm{SD})$ & \\
Time since diagnosis $(\mathrm{mean} \pm \mathrm{SD})(\mathrm{years})$ & $6.6 \pm 5.8$
\end{tabular}

Prior glucose-lowering agents

(in addition to metformin) (\% of patients)

$\begin{array}{lc}\text { Sulfonylurea } & 32.8 \\ \text { Repaglinide } & 13.7 \\ \text { Glitazones } & 16.1 \\ \text { GLP-1 analog } & 0.3\end{array}$

Clinical status at enrollment (mean \pm SD)

Glycemia

$\begin{array}{ll}\text { HbAlc }(\%) & 8.2 \pm 1.3 \\ \text { FPG }(\mathrm{mg} / \mathrm{dL}) & 171.0 \pm 53.3 \\ \text { Lipids }(\mathrm{mg} / \mathrm{dL}) & \\ \text { Total cholesterol } & 193.0 \pm 44.4 \\ \text { LDL } & 107.0 \pm 38.2 \\ \text { HDL } & 50.4 \pm 18.8 \\ \text { Triglycerides } & 180.6 \pm 93.8\end{array}$

Liver enzymes (U/L)

\begin{tabular}{ll} 
AST & $29.3 \pm 20.3$ \\
ALT & $34.4 \pm 27.6$ \\
Blood pressure $(\mathrm{mmHg})$ & \\
Systolic & $135.2 \pm 12.8$ \\
Diastolic & $80.7 \pm 8.4$ \\
\hline
\end{tabular}

Table 1 continued

Patient demographics and clinical status Values

\section{Comorbidities ( $\%$ of patients) ${ }^{a}$}

Dyslipidemia

Cardiac pathology

Renal pathology

14.1

Peripheral artery disease

12.3

Psychiatric disorder

Neuropathy

11.8

Cerebrovascular pathology

10.6

Diabetic eye disease

6.2

Skin ulceration

5.2

Amputation

1.0

Risk factors (\% of patients)

Lack of regular exercise

Obesity

71.4

Persistent high carbohydrate intake

56.6

Family history of diabetes

39.1

Active smoker

Excessive alcohol intake

16.3

ALT Alanine aminotransferase, AST aspartate aminotransferase, FPG Fasting plasma glucose, GLP-1 glucagonlike peptide-1, HbAlc glycated hemoglobin, $H D L$ highdensity lipoprotein cholesterol, $L D L$ low-density lipoprotein cholesterol, $S D$ standard deviation

a Categories are not mutually exclusive. Patients may have had more than one condition. Percentage was calculated on number of valid reports

whom a median of $30 \%$ had uncontrolled HbA1c (defined as having a HbA1c of $>7 \%$ ). The median time spent on a first visit with a newly diagnosed T2DM patient was $20 \mathrm{~min}$, whereas the median time spent on a visit for a diagnosed patient was 15 min. Physicians tended to initiate treatment at a median FPG of $126 \mathrm{mg} / \mathrm{dL}$ and a median $\mathrm{HbA} 1 \mathrm{c}$ of $7 \%$ using primarily one or two oral agents. Most of them considered a family history of T2DM (82.5\%), obesity (80.9\%), dyslipidemia (75.5\%) and 
hypertension (69.1\%) as important factors influencing the decision to screen patients for T2DM. HbA1c level was considered to be the most important factor in the management of T2DM by the majority of physicians $(54.5 \%)$, followed by fasting glycemia (12.4\%). The following patient comorbidities were considered by the physicians as leading to a more aggressive glycemic control: hypertension (87.0\%), previous cardiovascular event $(82.8 \%)$, renal disease $(81.2 \%)$, retinopathy by diabetes $(78.0 \%)$ and hyperlipidemia $(71.7 \%)$. Of the participating physicians, 38.9 and $33.4 \%$ discuss T2DM and its complications with the patient at least every 2 or 6 months, respectively, whereas 42.0 and $33.1 \%$ of them discuss the glucoselowering medication with their patient at least every 2 or 6 months, respectively. Almost onequarter $(23.9 \%)$ of the physicians had never heard of the EASD guidelines, and $6.4 \%$ stated not being interested in these guidelines. Only $18.5 \%$ reported to know and use the EASD guidelines in their clinical practice.

\section{Glucose-Lowering Treatment Patterns}

Per the inclusion criteria, all patients had been treated with metformin, with or without other agents, prior to enrollment. On average, patients' glucose-lowering medication had been changed $2.5 \pm 1.6$ times, and patients had been on $1.9 \pm 0.8$ different agents before treatment with vildagliptin was initiated. As shown in Table 2, most patients were started on vildagliptin in combination with metformin $(92.9 \%)$, but some $(7.1 \%)$ were started on vildagliptin only. At the time of enrollment, the most used concomitant glucose-lowering medications were glitazones and sulphonylurea (16.1 and $12.1 \%$, respectively, of the patients). Among antihypertensive agents prescribed, $57.7 \%$ of patients were prescribed either an angiotensin receptor blocker or an angiotensin converting enzyme inhibitor, whereas betablockers were prescribed in $31.0 \%$ of the patients. Consistent with the cardio-metabolic risk profile, $68.0 \%$ of patients were on statin therapy, while about one-half of patients (51.1\%) were prescribed low-dose aspirin.
At visit 2, 22.7\% of patients were switched to the SPC vildagliptin/metformin; a similar rate (22.1\%) was observed at visit 3 . As a result, the proportions of patients on the free regimen of vildagliptin and metformin therapy decreased to about two-thirds of patients at visit 2 (69.1\%) and visit $3(64.4 \%)$. The use of concomitant glucose-lowering medications remained constant with the exception of the class of glitazones: as a result of the initiation of vildagliptin, $\pm 13 \%$ of the patients were taken off glitazones, so the percentage of patients treated with glitazones decreased from $16.1 \%$ at baseline to 2.4 and $2.8 \%$ at visit 2 and 3 , respectively.

\section{Non-Adherence}

When asked about their medication behavior in the preceding 4 weeks, the proportion of patients giving answers indicative of non-adherence decreased from baseline to visit 2 and 3 for all three adherence behaviors of interest, i.e. not having taken medication, skipping several doses and taking medication more than $2 \mathrm{~h}$ off schedule (all $p<0.01$ ), as well as for the mean composite of frequency of non-adherence $(p<0.0001)$ (Table 2). Mean patient and physician VAS ratings of adherence increased by 3.1 and $5.3 \%$, respectively, from baseline to visit $3(p<0.0001)$, and the VAS ratings of patient and physician were correlated highly at each of the three visits (all $p<0.0001$ ). The most important reasons for patients' poor adherence were forgetfulness of prescriptions (33.4\%), lack of understanding of the importance of longterm continuing treatment (21.3\%) and refusal to accept the chronic nature of the disease $(14.0 \%)$. Suggestions given by the physicians to improve patient adherence were dosage simplification (31.5\%) and provision of information to the patient $(29.3 \%)$.

\section{Clinical Outcomes}

Effectiveness of vildagliptin was analyzed based on 1230 patients whose HbA1c levels could be obtained for all three time points of the study (at baseline and at visits 2 and 3). At initiation 
Table 2 Treatment patterns and patient adherence at each time point

Treatment patterns and patient adherence

\section{Treatments (\% of patients)
Vildagliptin only (monotherapy)}

Vildagliptin + metformin

SPC vildagliptin/metformin

No treatment

\section{Study time points}

Baseline $105 \pm 15$ days

$\begin{array}{lll}7.1 & 6.2 & 10.5 \\ 92.9 & 69.1 & 64.4 \\ - & 22.7 & 22.1 \\ - & 2.0 & 3.0\end{array}$

Concomitant glucose-lowering agents (\% of patients)

$\begin{array}{llll}\text { Sulfonylurea } & 12.1 & 12.0 & 11.2 \\ \text { Repaglinide } & 7.6 & 7.1 & 6.6 \\ \text { Glitazones } & 16.1 & 2.4 & 2.8 \\ \text { GLP-1 analog } & 1.5 & 1.5 & 1.4\end{array}$

Other concomitant medications (at baseline) (\% of patients)

Blood pressure-lowering agents (\% of patients)

Beta-blocker $\quad 31.0$

Angiotensin converting enzyme inhibitor 28.9

Angiotensin 2 receptor blocker $\quad 28.8$

Diuretics 25.5

Calcium antagonist $\quad 21.6$

Direct renal inhibitor $\quad 1.7$

Cholesterol-lowering agents (\% of patients)

Statins $\quad 68.0$

Fibrates $\quad 7.4$

Antiplatelet agents (\%)

Low-dose aspirin $\quad 51.1$

$\begin{array}{ll}\text { Clopidogrel } & 4.7\end{array}$

\section{Adherence}

\% Patients acknowledging in prior 4 weeks:

Not having taking medication* $\quad 35.0$

$\begin{array}{lll}21.5 & 16.1 & 12.0\end{array}$

Skipping several doses*

25.3

21.8

20.4

Frequency of non-adherence $(0-5)(\mathrm{M} \pm \mathrm{SD})^{*}$

$0.62 \pm 1.0$

$0.45 \pm 0.8$

$0.37 \pm 0.8$

VAS rating (0-100) of patient adherence (mean \pm SD)

By patient*

$84.1 \pm 13.5$

$86.5 \pm 11.5$

$87.2 \pm 11.8$ 
Table 2 continued

\begin{tabular}{|c|c|c|c|}
\hline \multirow[t]{2}{*}{ Treatment patterns and patient adherence } & \multicolumn{3}{|c|}{ Study time points } \\
\hline & Baseline & $105 \pm 15$ days & $180 \pm 15$ days \\
\hline By physician* & $80.5 \pm 16.0$ & $84.7 \pm 13.9$ & $85.8 \pm 13.1$ \\
\hline Correlation $^{\mathrm{a}}$ & 0.76 & 0.79 & 0.81 \\
\hline
\end{tabular}

$S P C$ Single pill combination, $V A S$ visual analog scale, GLP-1 glucagon-like peptide-1

${ }^{*}$, ^ Difference between baseline and visits 2 and 3 was significant at ${ }^{*} p<0.0001$ and $\wedge p=0.0090$

${ }^{a}$ VAS ratings of patient and physician were highly correlated highly at each of the three visits $($ all $p<0.0001)$.

of vildagliptin therapy, the mean HbA1c was $8.2 \pm 1.3 \%$, and this value decreased significantly to $7.4 \pm 1.0$ and $7.2 \pm 1.0 \%$ at 105 (visit $2)$ and 180 days (visit 3$)(p<0.0001)$, respectively. In addition, the proportion of patients who achieved the recommended glycemic target $(\mathrm{HbA1c}<7 \%)$ increased from $8.6 \%$ at initiation of vildagliptin therapy to 35 and $44.6 \%$ at 105 and 180 days post-initiation of vildagliptin (all $p<0.0001$ ), respectively (Fig. 2a, c). HbA1c goal attainment rates were highest among patients with baseline HbA1c of $<8.0 \%$ at initiation (Fig. 2e). In parallel, mean FPG levels decreased from $171.0 \pm 53.3 \mathrm{mg} / \mathrm{dL}$ at baseline to $145.3 \pm 44.4$ and $141.1 \pm 44.0 \mathrm{mg} / \mathrm{dL}$ at 105 and 180 days, respectively, whereas FPG goal achievement (FPG $<126 \mathrm{mg} / \mathrm{dl}$ ) rate increased from $14.2 \%$ before initiation of vildagliptin therapy to 37.5 and $42.8 \%$ at days 105 and 180 post-initiation of vildagliptin $(p<0.0001)$, respectively (Fig. 2b, d).

As summarized in Table 3, mean BMI, total cholesterol, LDL-cholesterol, triglycerides, systolic blood pressure and ALT and AST values all decreased significantly from baseline to 180 days after initiation of vildagliptin, while no changes could be observed for HDL and diastolic blood pressure values. Importantly, waist circumference, a simple and valid marker for abdominal obesity, decreased significantly from baseline to day 180 , both in male and female patients.

Patients who switched to the SPC of vildagliptin and metformin showed no difference in mean $\mathrm{HbA1c}$ at study end compared to those who remained on vildagliptin and metformin separately. However, the switched patients showed greater reductions in mean FPG $(p<0.01)$, and a higher proportion of these patients achieved the HbA1c (48.5 vs. $42.9 \%)$ $(p<0.01)$ and FPG (56.6 vs. $38.8 \%)(p<0.001)$ goals despite similar patient-reported adherence rates. Compared to non-elderly patients, patients aged $>65$ years evidenced $\mathrm{HbA} 1 \mathrm{c}$ and FPG levels that were between 0.18 and $0.28 \%$ $(p<0.001)$, and between 3 and $6 \mathrm{mg} / \mathrm{dL}$ $(p<0.05)$, respectively lower. Moreover, compared to patients aged $<65$ years, those aged $\geq$ 65 years had consistently higher HbA1c goal achievement rates at baseline (11.4 vs. $6.5 \%)$, 105 days post-initiation of vildagliptin (37.6 vs. $32.9 \%)$ and 180 days post-initiation of vildagliptin ( 47.8 vs. $41.8 \%$; all $p<0.01)$, but not higher FPG goal achievement rates.

\section{Safety}

Thirty-seven patients (2.4\%) reported a total of 56 AEs, mainly gastro-intestinal AEs $(n=24)$, whereas two cases of hypoglycemia were reported. Seventeen AEs were classified as SAEs, including three cases of death. Only one SAE, i.e. anorexia and weight loss, was suspected to be vildagliptin-related; this SAE was considered to be a sign of intolerance to vildagliptin, and treatment was stopped during hospitalization. $\mathrm{AE} / \mathrm{SAE}$ rates and liver enzyme levels for elderly and non-elderly patients were statistically similar, as were AE/SAE rates for patients switched to the SPC vildagliptin/metformin. 

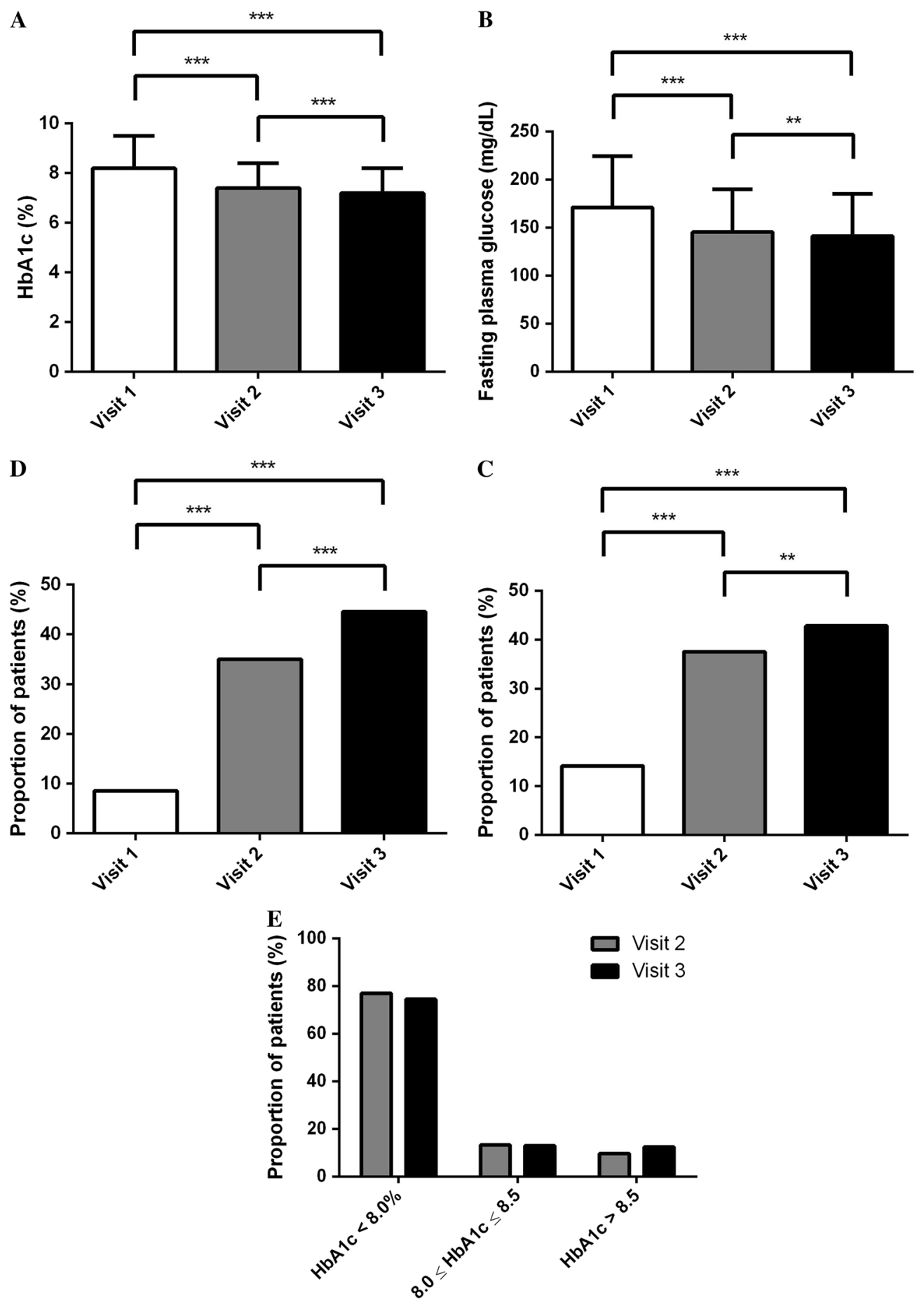

Fig. 2 Changes in HbAlc and fasting plasma glucose (FPG) levels. a, b HbA1c (a) and FPG (b) levels during visit 1 (baseline visit) and follow-up visits 2 and 3 at days 105 and 180 post-initiation of vildagliptin therapy, respectively. c, d Proportion of patients who reached glycemic goals of HbAlc $<7 \cdot 0 \%$ (c) and FPG $<126 \mathrm{mg} /$
$\mathrm{dL}$ (d) at visits 1, 2 or 3. e Proportion of patients who reached the glycemic goals of HbAlc $<7.0 \%$ at visit 2 or 3 according to HbAlc levels at baseline. Bars and whiskers represent the mean and standard deviation, respectively. Asterisks above bars indicate significant differences between study time points at ${ }^{* *} p<0.01$; and ${ }^{* * *} p<0.001$ 
Table 3 Evolution of the other clinical outcomes

\begin{tabular}{|c|c|c|c|c|c|}
\hline Clinical parameters & $\begin{array}{l}\text { Baseline } \\
(\text { mean } \pm \text { SD })\end{array}$ & $\begin{array}{l}105 \pm 15 \text { days } \\
(\text { mean } \pm S D)\end{array}$ & $\begin{array}{l}180 \pm 15 \text { days } \\
(\text { mean } \pm S D)\end{array}$ & $p^{a}$ & $p^{b}$ \\
\hline Body mass index $\left(\mathrm{kg} / \mathrm{m}^{2}\right)$ & $30.2 \pm 5.6$ & $29.7 \pm 5.2$ & $29.2 \pm 5.1$ & $<0.0001$ & $<0.0001$ \\
\hline $\begin{array}{l}\text { Waist circumference }(\mathrm{cm}) \\
\text { male patients }\end{array}$ & $109.2 \pm 16.4$ & $108.2 \pm 16.3$ & $107.1 \pm 15.8$ & $<0.0001$ & 0.0011 \\
\hline $\begin{array}{l}\text { Waist circumference }(\mathrm{cm}) \\
\text { female patients }\end{array}$ & $103.2 \pm 16.2$ & $102.0 \pm 16.7$ & $101.3 \pm 18.5$ & $<0.01$ & ns \\
\hline Total cholesterol $(\mathrm{mg} / \mathrm{dL})$ & $193.0 \pm 44.4$ & $183.5 \pm 38.7$ & $179.9 \pm 36.8$ & $<0.0001$ & $<0.0001$ \\
\hline $\mathrm{LDL}(\mathrm{mg} / \mathrm{dL})$ & $107.0 \pm 38.2$ & $102.8 \pm 35.2$ & $99.0 \pm 33.0$ & 0.0003 & $<0.0001$ \\
\hline $\mathrm{HDL}(\mathrm{mg} / \mathrm{dL})$ & $50.4 \pm 18.9$ & $51.0 \pm 18.1$ & $51.2 \pm 15.8$ & ns & 0.02 \\
\hline Triglycerides $(\mathrm{mg} / \mathrm{dL})$ & $180.9 \pm 93.8$ & $166.3 \pm 82.7$ & $162.9 \pm 86.8$ & $<0.0001$ & $<0.0001$ \\
\hline $\begin{array}{l}\text { Systolic blood pressure } \\
\quad(\mathrm{mmHg})\end{array}$ & $135.2 \pm 12.8$ & $133.2 \pm 10.9$ & $132.3 \pm 10.1$ & $<0.0001$ & $<0.0001$ \\
\hline $\begin{array}{l}\text { Diastolic blood pressure } \\
\quad(\mathrm{mmHg})\end{array}$ & $80.7 \pm 8.4$ & $80.4 \pm 7.2$ & $79.9 \pm 7.0$ & ns & $<0.0001$ \\
\hline $\operatorname{ALT}(\mathrm{U} / \mathrm{L})$ & $34.4 \pm 27.6$ & $30.7 \pm 20.0$ & $30.8 \pm 19.8$ & $<0.0001$ & 0.0004 \\
\hline $\operatorname{AST}(\mathrm{U} / \mathrm{L})$ & $29.3 \pm 20.3$ & $27.4 \pm 15.5$ & $27.4 \pm 13.8$ & 0.009 & $\mathrm{~ns}$ \\
\hline
\end{tabular}

ns Non-significant, $A L T$ alanine aminotransferase, $A S T$ aspartate aminotransferase, $H D L$ high-density lipoprotein, $L D L$ low-density lipoprotein

${ }^{a} p$ value vs. baseline

b $p$ value $180 \pm 15$ days vs. $105 \pm 15$ days

\section{DISCUSSION}

The G-FORCE study was conducted to provide real-world data on the effectiveness and safety profile of vildagliptin in patients with uncontrolled T2DM who had been treated with metformin. Data on patient-related factors determining adherence as well as on physicianrelated parameters influencing the general management of T2DM were also collected. Vildagliptin in a free dose regimen or SPC with metformin demonstrated significant improvements in glycemic outcomes over a 6-month period without changes in safety and tolerability. In addition, cardiovascular risk factors, such as BMI, blood pressure and serum lipid levels, were decreased during the 6-month treatment period with vildagliptin, suggesting an improved cardio-metabolic profile. These results obtained in a real-world setting clearly confirm the results from randomized clinical trials (RCTs) and provide important information regarding the use and effectiveness of vildagliptin in daily clinical practice.

Several RCTs have shown that vildagliptin is well tolerated and produces clinically meaningful, decreases in HbA1c and FPG in patients with T2DM inadequately controlled by metformin $[13,24]$. While RCTs are considered tp be the gold standard for establishing efficacy, they have several drawbacks, leading to an increased interest in real-world data covering evidence on the relative benefits and harms of interventions in everyday circumstances [25]. To better understand the real-world clinical effectiveness and safety of vildagliptin in combination with metformin, we set up this prospective, observational study.

Treatment with vildagliptin decreased HbA1c levels by 0.8 and $1.0 \%$ after 105 and 
180 days of treatment, respectively. These values are comparable to those values obtained in RCTs, showing a reduction in HbA1c level of 0.9 and $1.1 \%$, respectively, after 24 and 52 weeks of treatment with vildagliptin in T2DM patients already treated with metformin [13, 14, 24]. In contrast, Ferrannini et al. only showed a $0.44 \%$ reduction in HbA1c levels after 52 weeks of treatment with vildagliptin [16]; this discrepancy can be explained by the substantial difference of $0.9 \%$ in baseline HbA1c level between this study and the G-FORCE study (baseline HbA1c was $7.3 \%$ in the study of Ferrannini et al. and $8.2 \%$ in the G-FORCE study). Moreover, our results are in line with those of a meta-analysis performed by DeFronzo et al. demonstrating that higher baseline HbA1c levels are associated with greater reductions in HbA1c levels, irrespective of class or mode of action of the drug [26]. Also, the HbA1c reduction seen in the present study confirms results from other observational studies with vildagliptin showing reductions in HbA1c level of between 0.8 and $1.19 \%$ for baseline HbA1c levels ranging from 7.8 to $8.2 \%$ [27-30]. A post-hoc analysis of the Belgian patients included in the EDGE study, a 1-year observational study with vildagliptin in T2DM patients with a baseline HbA1C of $8.4 \%$, revealed a decrease of $0.81 \%$ in $\mathrm{HbA} 1 \mathrm{c}$, a value comparable to that achieved in the present study [31].

Interestingly, the HbA1c goal achievement rate of $44.6 \%$ at 180 days associated with vildagliptin treatment in the present study was higher than the $27 \%$ obtained in the 24 -week study by Bolli et al., despite similar baseline HbA1c levels [14]. Bosi et al. demonstrated an HbA1c goal achievement rate of $54.4 \%$ for patients who started with HbA1c $\leq 7.9 \%$ [13], while the G-FORCE study showed a rate of $74.5 \%$ for patients in the same HbA1c category. Ferrannini et al. reported slightly higher goal achievement rates of $54 \%$ in their 52-week investigation [16], but this can be explained by the lower HbA1c baseline value of $7.3 \%$ as compared to $8.2 \%$ in the G-FORCE study. Compared to other real-world observational studies, we achieved similar goal rates in our study: for example, in the VILDA [30] and VICTORY [30] studies, 44.9 and $58.9 \%$ of the patients, respectively, achieved the glycemic target after 6 months of treatment with vildagliptin, starting from an HbA1c baseline of 7.8 and $8 \%$, respectively.

In our study, glycemic improvement patterns among elderly patients were comparable to those among non-elderly patients, but the former achieved lower absolute HbA1c and FPG levels and a higher percentage achieved the HbA1c goal with no differences in safety outcomes. Interestingly, patients switched to the SPC of vildagliptin and metformin showed no difference in mean HbA1c at study end compared to those who remained on vildagliptin and metformin, but the switched patients showed greater reductions in mean FPG and higher HbA1c and FPG goal achievement rates despite similar patient-reported adherence rates. These results confirm the previous findings of the VICTORY study showing a higher proportion of patients achieving the glycemic goal when treated with the SPC of vildaliptin and metformin as compared to the free regimen [30]. In short, both vildagliptin and the SPC of vildagliptin and metformin are effective agents in the management of diabetes across the age spectrum, while the SPC of vildagliptin/metformin can provide a more convenient alternative that ensures at least comparable effectiveness and safety.

Interestingly, not only were improvements in glycemia and glycemic control achieved, so were improvements in terms of body weight and serum lipid levels, suggesting an improved cardiovascular risk profile. While rather stable body weight and lipid parameters were observed in RCTs $[13,16,24]$, small improvements in body weight and lipid parameters were observed in other observational studies with vildagliptin [27-29]. The G-FORCE study also showed a mild reduction of systolic blood pressure of $2 \mathrm{mmHg}$, but as it has been demonstrated before that even a small reduction can have a significant impact on cardiovascular risk reduction [32], the combination of a lower body weight, decreased waist circumference, improved lipid profile and slightly reduced blood pressure might be an added value to the glycemic effectiveness of vildagliptin. 
Despite the benefits of oral glucose-lowering agents, our study and other studies have indicated that recommended glycemic goals are achieved by less than $50 \%$ of patients, possibly due to decreased adherence to therapies [33]. Non-adherence rates in the present study were substantial and in line with known estimates for persons living with diabetes [34], but importantly the percentage of patients not taking medication, taking it off schedule or skipping several doses significantly decreased after the initiation of vildagliptin. Interestingly, patients switched to the SPC of vildagliptin and metformin were similarly non-adherent as those on the free regimen. However, it should be noted that the VAS rating, the technique used in this study to determine medication adherence, is less accurate than direct measurements such as pill count and the use of a medication events monitoring system; consequently, our results on non-adherence need to be seen as exploratory [35]. As has been demonstrated, there is an inverse relationship between taking a prescribed oral glucose-lowering agent and HbA1c level, with each $10 \%$ increase in adherence to oral glucose-lowering agents associated with a $0.1 \%$ decrease in HbA1c [36], while medication nonadherence also increases the risk for all-cause hospitalization and mortality [37]. These results demonstrate that more innovative methods are needed to assist those patients who fail in their medication.

\section{CONCLUSION}

The data from the present study show that both the free dose regimen of vildagliptin and metformin and the SPC of vildagliptin and metformin are effective agents in the glycemic management of T2DM, while the SPC additionally leads to an increased proportion of patients reaching their glycemic goals and lower FPG levels with comparable effectiveness and tolerability as the free dose regimen. Importantly, this observational study shows comparable results in terms of effectiveness and safety between uncontrolled conditions in real-life clinical practice and controlled conditions in RCTs. Nevertheless, despite international guidelines focusing on an early intensification of glucose-lowering therapies, this study clearly revealed a high proportion of suboptimally treated patients in real life. Therefore, both endocrinologists and general practitioners should be more aggressive in the treatment of T2DM.

\section{ACKNOWLEDGEMENTS}

The authors thank the study participants and investigators for their participation.

Funding. Sponsorship for this study and article processing charges were funded by Novartis Pharma. All authors had full access to all of the data in this study and take complete responsibility for the integrity of the data and accuracy of the data analysis.

Editorial Assistance. The authors thank C. Verhestraeten of Novartis Pharma for proofreading and editorial assistance. This was funded by Novartis Pharma.

Authorship. All named authors meet the International Committee of Medical Journal Editors (ICMJE) criteria for authorship for this article, take responsibility for the integrity of the work as a whole, and have given their approval for this version to be published.

Disclosures. Luc Van Gaal has served on Novartis advisory boards and have received travel support for conference attendance from Novartis Pharma. Michel P. Hermans has served on Novartis advisory boards and have received travel support for conference attendance from Novartis Pharma. Evis Daci is an employee of Novartis Pharma. Lut De Meester is an employee of Novartis Pharma. Stefaan Vancayzeele is an employee of Novartis Pharma. Michael Maris is an employee of Novartis Pharma. Karen MacDonald is an employee of Matrix45. Kris Denhaerynck is an employee of Matrix45. Ivo Abraham is an employee of Matrix45. 
Compliance with Ethics Guidelines. The study was approved by the Medical Ethical Committee of Antwerp University Hospital (Belgium). All procedures performed in studies involving human participants were in accordance with the ethical standards of the Antwerp University Hospital (Belgium) and with the 1964 Helsinki declaration and its later amendments or comparable ethical standards. All subjects (or their legal guardian) gave written informed consent before participating in the study.

Open Access. This article is distributed under the terms of the Creative Commons Attribution-NonCommercial 4.0 International License (http://creativecommons.org/licenses/ by-nc/4.0/), which permits any noncommercial use, distribution, and reproduction in any medium, provided you give appropriate credit to the original author(s) and the source, provide a link to the Creative Commons license, and indicate if changes were made.

\section{REFERENCES}

1. International Diabetes Federation (IDF). IDF diabetes atlas 8th edition. 2017. https://www. diabetesatlas.org

2. Katsarou A, Gudbjornsdottir S, Rawshani A, et al. Type 1 diabetes mellitus. Nat Rev Dis Primers. 2017;3:17016.

3. DeFronzo RA, Ferrannini E, Groop L, et al. Type 2 diabetes mellitus. Nat Rev Dis Primers. 2015;1:15019.

4. Davies MJ, D'Alessio DA, Fradkin J, et al. Management of hyperglycemia in type 2 diabetes, 2018. A consensus report by the American Diabetes Association (ADA) and the European Association for the Study of Diabetes (EASD). Diabetes Care. 2018;41(12):2669-701.

5. Duckworth W, Abraira C, Moritz T, et al. Glucose control and vascular complications in veterans with type 2 diabetes. N Engl J Med. 2009;360(2):129-39.

6. Ismail-Beigi F, Craven T, Banerji MA, et al. Effect of intensive treatment of hyperglycaemia on microvascular outcomes in type 2 diabetes: an analysis of the ACCORD randomised trial. Lancet. 2010;376(9739):419-30.

7. UK Prospective Diabetes Study (UKPDS) Group. Effect of intensive blood-glucose control with metformin on complications in overweight patients with type 2 diabetes (UKPDS 34). Lancet. 1998;352(9131):854-65.

8. American Diabetes Association. Standards of Medical Care in Diabetes. 2018;41[Suppl 1]:S73-85.

9. Villhauer EB, Brinkman JA, Naderi GB et al. 1-[[(3hydroxy-1-adamantyl)amino]acetyl]-2-cyano-(S)pyrrolidine: a potent, selective, and orally bioavailable dipeptidyl peptidase IV inhibitor with antihyperglycemic properties. J Med Chem. 2003;46(13):2774-899.

10. Balas B, Baig MR, Watson C, et al. The dipeptidyl peptidase IV inhibitor vildagliptin suppresses endogenous glucose production and enhances islet function after single-dose administration in type 2 diabetic patients. J Clin Endocrinol Metab. 2007;92(4):1249-55

11. Ahren B, Pacini G, Foley JE, Schweizer A. Improved meal-related beta-cell function and insulin sensitivity by the dipeptidyl peptidase-IV inhibitor vildagliptin in metformin-treated patients with type 2 diabetes over 1 year. Diabetes Care. 2005;28(8):1936-40.

12. Pi-Sunyer FX, Schweizer A, Mills D, Dejager S. Efficacy and tolerability of vildagliptin monotherapy in drug-naive patients with type 2 diabetes. Diabetes Res Clin Pract. 2007;76(1):132-8.

13. Bosi E, Camisasca RP, Collober C, Rochotte E, Garber AJ. Effects of vildagliptin on glucose control over 24 weeks in patients with type 2 diabetes inadequately controlled with metformin. Diabetes Care. 2007;30(4):890-5.

14. Bolli G, Dotta F, Rochotte E, Cohen SE. Efficacy and tolerability of vildagliptin vs. pioglitazone when added to metformin: a 24-week, randomized, double-blind study. Diabetes Obes Metab. 2008;10(1):82-90.

15. Garber AJ, Schweizer A, Baron MA, Rochotte E, Dejager S. Vildagliptin in combination with pioglitazone improves glycaemic control in patients with type 2 diabetes failing thiazolidinedione monotherapy: a randomized, placebo-controlled study. Diabetes Obes Metab. 2007;9(2):166-74.

16. Ferrannini E, Fonseca V, Zinman B, et al. Fifty-twoweek efficacy and safety of vildagliptin vs. glimepiride in patients with type 2 diabetes mellitus 
inadequately controlled on metformin monotherapy. Diabetes Obes Metab. 2009;11(2):157-66.

17. Croxtall JD, Keam SJ. Vildagliptin: a review of its use in the management of type 2 diabetes mellitus. Drugs. 2008;68(16):2387-409.

18. Wilkinson S, Douglas I, Stirnadel-Farrant $\mathrm{H}$, et al. Changing use of antidiabetic drugs in the UK: trends in prescribing 2000-2017. BMJ Open. 2018;8(7):e022768.

19. Chu WM, Ho HE, Huang $\mathrm{KH}$, et al. The prescribing trend of oral antidiabetic agents for type 2 diabetes in Taiwan: an 8-year population-based study. Medicine (Baltimore). 2017;96(43):e8257.

20. Montvida O, Shaw J, Atherton JJ, Stringer F, Paul SK. Long-term trends in antidiabetes drug usage in the US: real-world evidence in patients newly diagnosed with type 2 diabetes. Diabetes Care. 2018;41(1):69-78.

21. RIZIV/INAMI. Consensus meeting: Het rationeel gebruik van de GLP-1 receptoragonisten bij type 2-diabetes. https://www.riziv.fgov.be/SiteCollection Documents/consensus_sprekersbrochure_201611 17.pdf.

22. Abraham I, MacDonald K, Hermans C, et al. Realworld effectiveness of valsartan on hypertension and total cardiovascular risk: review and implications of a translational research program. Vasc Health Risk Manag. 2011;7:209-35.

23. Dobbels F, Berben L, De Geest S, et al. The psychometric properties and practicability of self-report instruments to identify medication nonadherence in adult transplant patients: a systematic review. Transplantation. 2010;90(2): 205-19.

24. Ahren B, Gomis R, Standl E, Mills D, Schweizer A. Twelve- and 52-week efficacy of the dipeptidyl peptidase IV inhibitor LAF237 in metformin-treated patients with type 2 diabetes. Diabetes Care. 2004;27(12):2874-80.

25. Mahajan R. Real world data: additional source for making clinical decisions. Int J Appl Basic Med Res. 2015;5(2):82.

26. DeFronzo RA, Stonehouse AH, Han J, Wintle ME. Relationship of baseline HbA1c and efficacy of current glucose-lowering therapies: a meta-analysis of randomized clinical trials. Diabet Med. 2010;27(3):309-17.
27. Bluher M, Kurz I, Dannenmaier S, Dworak M. Efficacy and safety of vildagliptin in clinical practiceresults of the PROVIL-study. World J Diabetes. 2012;3(9):161-9.

28. Simon D, Detournay B, Eschwege E, et al. Use of vildagliptin in management of type 2 diabetes: effectiveness, treatment persistence and safety from the 2-year real-life VILDA study. Diabetes Ther. 2014;5(1):207-24.

29. Mathieu C, Barnett AH, Brath H, et al. Effectiveness and tolerability of second-line therapy with vildagliptin vs. other oral agents in type 2 diabetes: a real-life worldwide observational study (EDGE). Int J Clin Pract. 2013;67(10):947-56.

30. Suh S, Song SO, Kim JH, Cho H, Lee WJ, Lee BW. Effectiveness of vildagliptin in clinical practice: pooled analysis of three Korean observational studies (the VICTORY Study). J Diabetes Res. 2017;2017:5282343.

31. Hoste J, Daci E, Mathieu C. Effectiveness and tolerability of second-line therapy with vildagliptin versus other oral agents in type 2 diabetes (EDGE): post-hoc subanalysis of the Belgian data. Acta Clin Belg. 2014;69(3):171-6.

32. Blood Pressure Lowering Treatment Trialists' Collaboration. Blood pressure-lowering treatment based on cardiovascular risk: a meta-analysis of individual patient data. Lancet. 2014;384(9943):591-8.

33. Garcia-Perez LE, Alvarez M, Dilla T, Gil-Guillen V, Orozco-Beltran D. Adherence to therapies in patients with type 2 diabetes. Diabetes Ther. 2013;4(2):175-94.

34. DiMatteo MR. Variations in patients' adherence to medical recommendations: a quantitative review of 50 years of research. Med Care. 2004;42(3):200-9.

35. Zeller A, Ramseier E, Teagtmeyer A, Battegay E. Patients' self-reported adherence to cardiovascular medication using electronic monitors as comparators. Hypertens Res. 2008;31(11):2037-43.

36. Rozenfeld Y, Hunt JS, Plauschinat C, Wong KS. Oral antidiabetic medication adherence and glycemic control in managed care. Am J Manag Care. 2008;14(2):71-5.

37. Ho PM, Rumsfeld JS, Masoudi FA, et al. Effect of medication nonadherence on hospitalization and mortality among patients with diabetes mellitus. Arch Intern Med. 2006;166(17):1836-41. 